\title{
Accuracy of Panoramic Dental X-Ray Imaging in Detection of Proximal Caries with Multiple Morpological Gradient (mMG) Method

\author{
Jufriadif $\mathrm{Na}{ }^{\circ}{ }^{\#}{ }^{\#}$ \\ \# Computer Science Faculty, Universitas Putra Indonesia YPTK Padang, 25221, Indonesia \\ E-mail: jufriadifnaam@gmail.com
}

\begin{abstract}
Dental caries is tooth decay caused by bacterial infection. This is commonly known as tooth decay. Classification of caries by location consists of; occlusal caries, proximal caries, root caries and caries enamel. Diagnosis of dental caries in general carried out with the help of radiographic images is called Dental X-Ray. Dental X-Ray consists of bitewing, Periapical and Panoramic. Identification of proximal caries using Dental Panoramic X-Ray lowest precision was compared with both other Dental X-Ray. This study aims to perform sharpening and improving the quality of information contained in the image of Panoramic Dental $X$-Ray to clarify the edges of the objects contained in the image, making it easier to identify and proximal caries severity. The methods and algorithms used are multiple Morphology Gradient (mMG). The results obtained are increased accuracy in identifying proximal caries $47.5 \%$. Based on the severity of it, that level of enamel $=47.37 \%$; dentin rate $=42.1 \%$ and the rate of dentin $=1.3 \%$. Accuracy level of accuracy in identifying proximal caries a higher level of email, so that patients with proximal caries early levels can be tackled early handling by the dentist.
\end{abstract}

Keywords - Proximal Caries; Caries; multiple Morphological Gradient (MMG); Panoramic X-Ray; Smoothing and Sharpening the Edges of Objects.

\section{INTRODUCTION}

Image pattern recognition is a science to classify or describe something by the quantitative measurement of the image or the nature of the object. The pattern itself is an entity defined, can be identified and given a name. Patterns can be a collection or monitoring and measurement results. It can be expressed in a vector or matrix notation [1]. In the image pattern recognition can also be done the selection process to get the kind of image that will be used in image processing [2]. Image used in this image processing, consists of various types of image file formats such as * .bmp, * .tif, * .png or * .jpg [3].

In medicine, image processing is an example of the application of information technology in the medical world. Information technology in the medical world increasingly broad and very important, such as CT Scan (Computed Tomography Scan) or sometimes called CAT scan (Computerized Axial Tomography Scan), which can be used to view the piece or a cross-section of the human body. Tomography is the process to produce a two-dimensional image of the object three-dimensional pieces of a number of one-dimensional scanning results. One of the concepts of information technology applied is to perform image processing to perform sharpening or improve the quality of information contained in the image, so it can be interpreted correctly by the human eye [4].

Panoramic Dental x-rays is a tool that produces a twodimensional image to help in finding the caries [5]. Dental caries is a process of chronic, regressive begins with the dissolution of minerals enamel, as a result of disruption of the balance between the enamel and surrounding areas caused by acid formation of microbes on the substrate (medium food for bacteria), followed by the onset of destruction of organic components which eventually happened cavitation or holes [6]. Hole created will cause the occurrence of damage to the tissues of the tooth ranging from enamel, dentin and to the pulpa. Tooth holes starting from the enamel to the pulpa spaces contain nerve fibers and blood vessels that are causing the pain [7], can even lead to heart disease and stroke [8].

Types of dental caries can be distinguished into four types, namely Oklusal, Proximal, Email and root [9]. The fourth type of caries, the most difficult to detect is the proximal caries [10]. This type cannot be detected visually or manually by simply using the tool of dental Explorers (diagnostic) teeth [11], so that the examination be radiography $\mathrm{x}$-ray image is indispensable to facilitate in identifying the proximal caries [12], [13]. 
The image of X-ray can show cavities (caries), teeth are hidden, and the bone that seems to disappear which can not be seen during visual examination [14], [15]. Types of Dental X-Ray used to detect dental caries consists of bitewing, periapical and panoramic [16].

The third type of Dental X-Ray on the least thoroughness in identifying proximal caries is Panoramic Dental X-Ray [17] - [25]. It is necessary for the process of improving the quality of the image. it is very important in medical imaging analysis, in order to identify further improved proximal caries.

\section{MATERIALS AND METHOD}

In the system of Image Processing in Medicine Dental Panoramic X-Ray, there are several stages of the process and sub-process in order to produce images that are easily observed and checked by the user in identifying proximal caries. The process steps starting from image acquisition, but this stage is not depicted in the system because the image required have been taken directly into the Radiology Dr M. Djamil Padang.

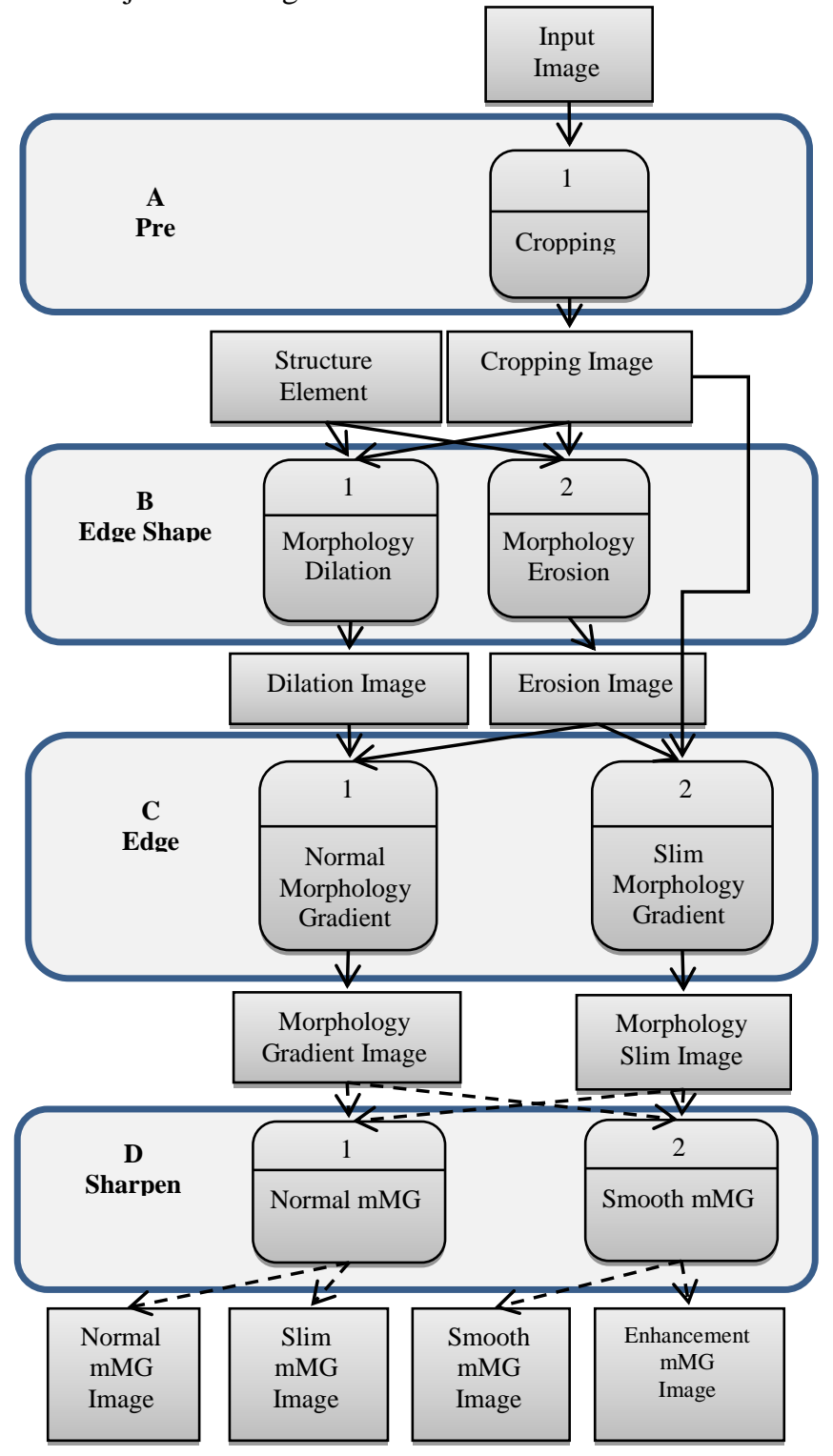

Fig. 1 Flow Diagram mMG Process
The image is processed is the image of Panoramic Dental X-Ray grayscale as a file format * .png and a pixel size of $2764 \times 1330$. The image consists of 101 files softcopy imagery. The image of the entire first examined by a dentist with the results of the image 58 patients with no caries; Image 27 patients with proximal caries; and 16 patients with caries image of the other.

Image processed by the system is just the image of patients suffering from proximal caries, image 27 files. This image file into the Input Image in the system. After that the process illustrated in the flow diagram $\mathrm{mMG}$ following process (Fig. 1).

\section{A. Pre-Processing}

Cropping is the process of cutting the image area, only the area required as input. it for further processing. Cropping technique used is the separation of horizontally and

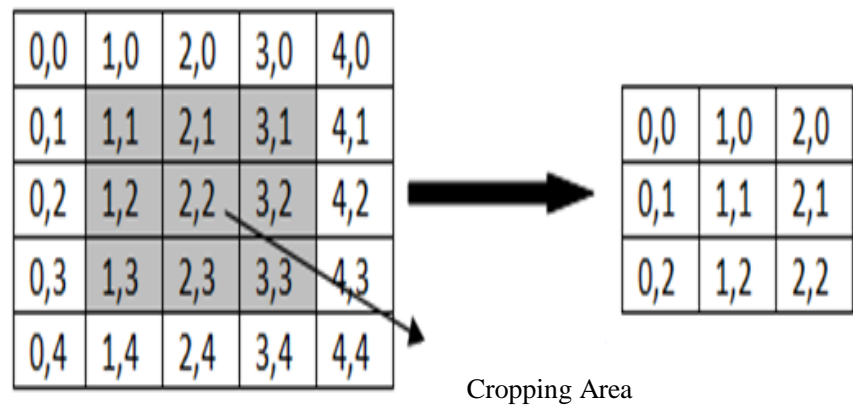

vertically and horizontally [26], [27], [28], [29], as shown in Fig. 2.

Fig. 2 Ilustration of Cropping [32]

Cropping is aiming to eliminate unnecessary parts and only get the required area (Region of Interest) in the next process. on the side and the top of the bottom image Panoramic Dental x-rays there are other parts that are not needed (noise). Teeth on image Panoramic Dental $x$-rays are present in one group, then for the cropping process required two point coordinates. One point coordinates for the part (point) top left (the position of the patient's right or $[\mathrm{R}]$ ight) and one point coordinates for the part (point) lower right (the position of the left side of the patient).

\section{B. Edge Shape}

Edge shape is the process to form the edges of objects on images by using the process morphology. Morphology is a process that uses mathematics as a tool for taking a useful image component to display and describe the region shape (such as boundaries, skeletons and convex hull). Mathematical morphology to function as a means of extracting useful image components in the representation and description of the form region. Process morphology that is used consists of morphology dilation morphology and erosion.

Morphological image processing is carried out in a way her passing a structuring element to an image. This way is almost the same as the image convolution. it aims to obtain information about the form of an image by adjusting the shape and size of a structural element. 
Structuring element (strel) can be likened with the mask on the image processing (not by morphology). Strel also have a shaft (also known as the point of origin). Point of origin is marked with a black dot. If there is no sign of black dots then assumed the point of origin is in the Centre of symmetry [31]. Strel has two key components, namely the shape and size, both of which greatly affects the results of the operations of the morphology and axis point also owns strel (also known as the point of origin). Point of origin is marked with the sign of the black box. Strel is used in this research is shaped disks with a size of $2 \times 2$.

\begin{tabular}{|l|l|}
\hline 1 & 1 \\
\hline 1 & 1 \\
\hline
\end{tabular}

Fig. 3 Element disk Stucture [2x2]

Effects of strel is:

- on morphological dilation, do not generate the object the more wide

- on the morphological erosion, then no object is missing.

\section{Morphology Dilation}

It's the process of widening or growing areas (objects). Area or object in question is an area that has a high intensity on image gray level. Image of A dilation by the structure of the elements of the matrix $B$ with dilation with notation as follows:

$$
A \oplus B=\left\{z \mid(B)_{z} \cap A \neq 0\right\}
$$

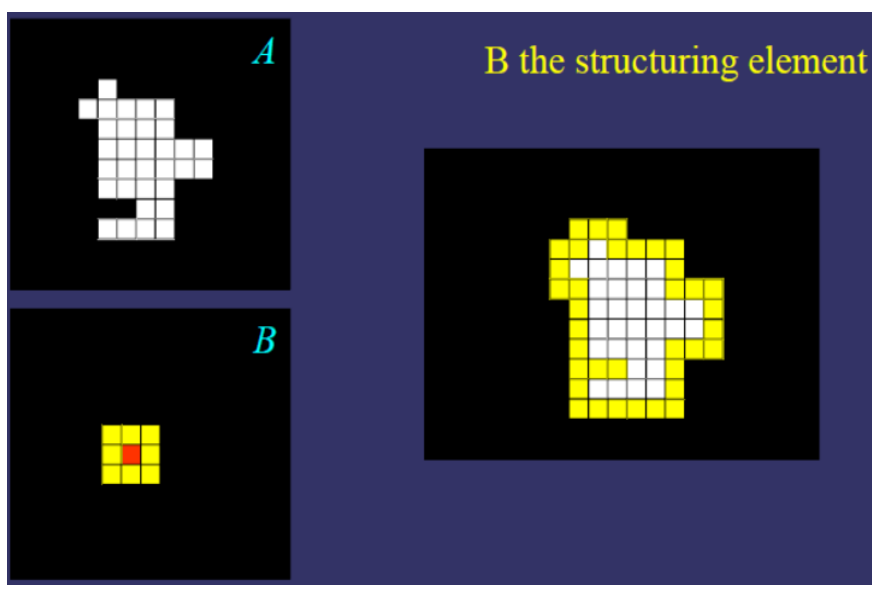

Fig. 4 Ilustration of Dilation

\section{Morphology Erosion}

This is a process shrink or diluting the area or object. An area or object in question is one that has high intensity on gray level image. This operation is opposite to the dilation operation. Erosion image A by matrix B element structure denoted as follows:

$$
A \Theta B=\left\{z \mid(B)_{z} \subseteq A\right\}
$$

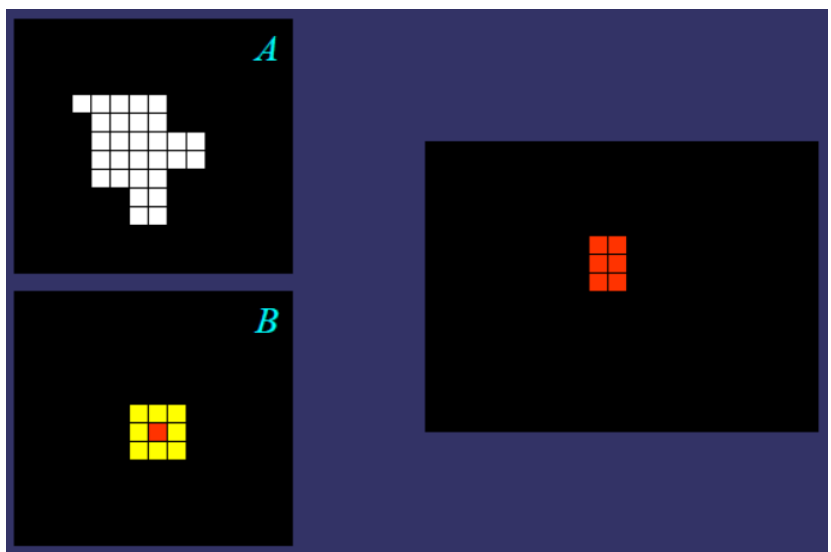

Fig. 5 Ilustration of Erosion

\section{Edge Detection}

The image data input in the form of a grayscale image Panoramic Dental X-Ray. It's processed to form the edges of objects, so that the objects contained in the image can be observed, especially the edges of objects caries. From a number of existing algorithms, the most appropriate use is morphological gradient. This process can widen and clarify the edges without removing or filtering out a lot of information.
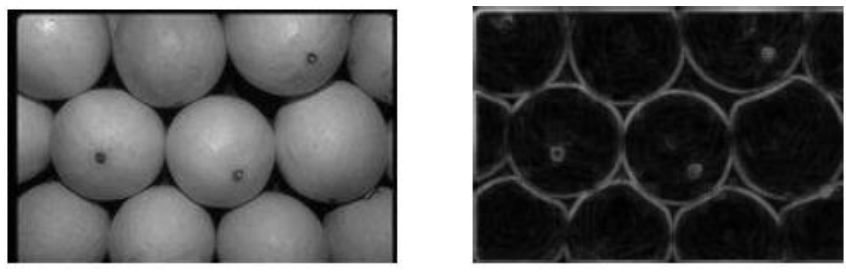

Fig. 6 Ilustration of Edge Detection [9]

Widening edge elements can be arranged through the structure and operation of morphological gradient itself. Operation morphological gradient used consisted of two, namely reducing the dilation results in erosion of the socalled normal morphological gradient; and reduce the cropping with the erosion of the so-called slim morphology gradient.

\section{Normal Morphology Gradient}

Normal morphology gradient is the process that produces an output in the form of an image obtained from a reduction in dilation results with the results of erosion. In this process can form the edges of the objects contained in the image. Notation morphological gradient is denoted as follows:

$$
g=(A \oplus B)-(A \ominus B)
$$

\section{Slim Morfologi Gradient}

Slim morphological gradient is the process that produces an output in the form of an image obtained from a reduction in cropping results with the results of erosion. In this process can form the edges of the objects contained in the image thinner than normal morphology gradient. Notation slim morphological gradient is denoted as follows:

$$
g=A-(A \oplus B)
$$




\section{Sharpen Edges}

Sharpen Edges is a process to clarify the edges of objects on the image. The process that occurs in Sharpen Edges consist of mMG normal and $\mathrm{mMG}$ smooth. MMG is a multiple Gradient Morphology that do the process over and over against the edge detection

At this stage of the process of edge detection. the image of Panoramic Dental x-rays, the resulting image has been able to form the edges of the object by either including the edge object caries, but looks a bit Dim. This is due to the intensity of caries objects contained in a lower gear than the object of the tooth itself. On the basis of this need for sharpening or increase the intensity from the edge of the object so that the object can be clearly recognized by the naked eye and each object in the image can be identified. To sharpen the edges of the objects, a process $\mathrm{mMG}$ with the following formula:

$$
m M G=m \cdot g
$$

$m$ is a lot of looping, this value based on the intensity of the image. The higher value of the an image intensity, then the value of $\mathrm{m}$ increases. The formula to get the value of $m$ with the following notations:

$$
m=\frac{\max (\max ((A \oplus B)-(A \Theta B)))}{w}
$$

$\mathrm{w}$ is bit.depth $\mathrm{x} 256$. Bit.depth a bit depth of an image containing information on the number of colors that exist in each pixel of the image. $m$ is a lot of looping process morphology gradient

TABLE I

STAGES OF THE PROCESS MMG

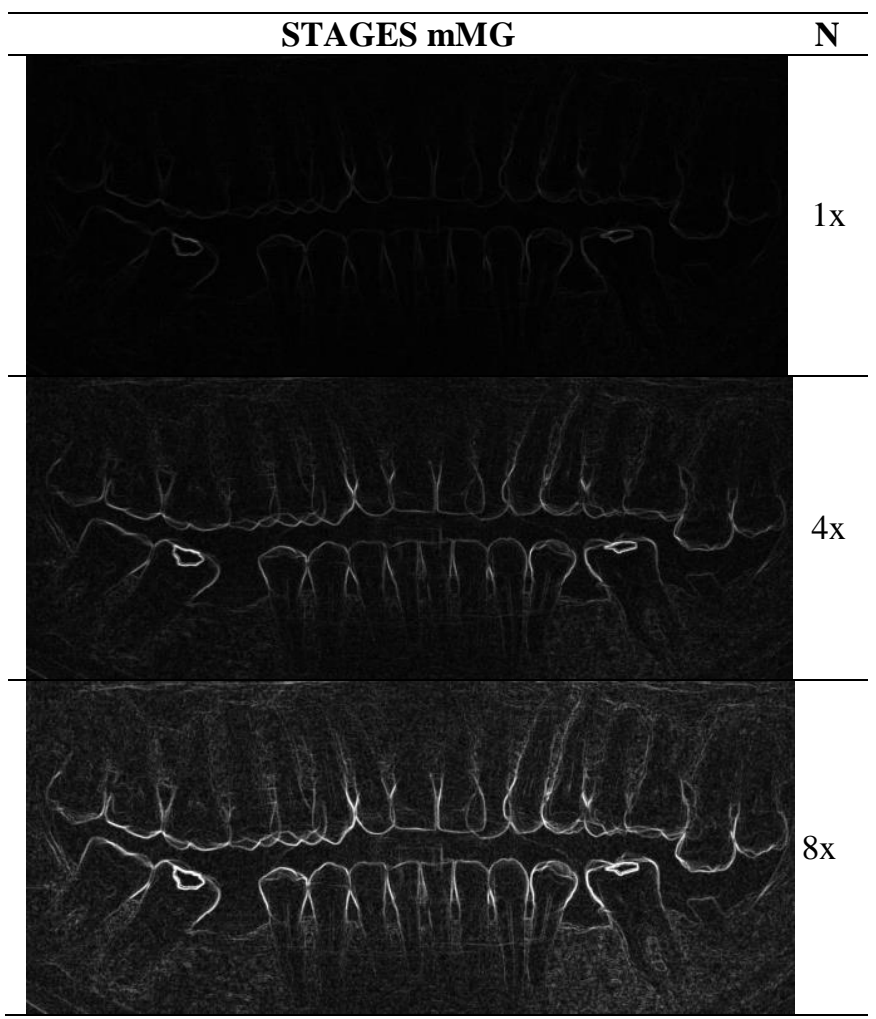

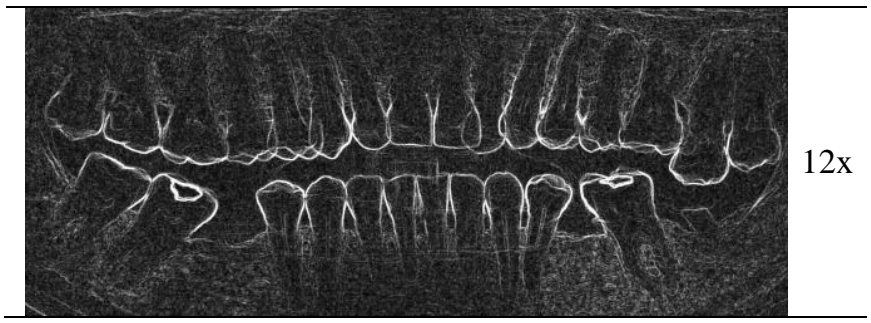

mMG process consists of two algorithms, yatu normal and smooth mMG [32].

\section{Normal $m M G$}

Normal mMG process by multiplying all pixel image of the edge detection with $\mathrm{m}$. The results obtained are two types of images, the appropriate type of edge detection is used, whether normal morphology gradient image of the normal form of $\mathrm{mMG}$ Image or slim-type morphology gradient image of the slim pickings in the form of $\mathrm{mMG}$ Image.

\section{Smooth $m M G$}

Smooth mMG functioning sharpens and smoothes the edges of objects in the image. The process is carried not all pixels multiplied by $\mathrm{m}$, But the pixels of value greater than or equal to the minimum value of Multi Thereshold

To obtain the minimum value Multi Threshold [33] used the formula

$$
T(A)=\left\{\begin{array}{l}
0, A<q \\
m, A \geq q
\end{array}\right.
$$

Where $0<q \leq A_{\max }$.

So the notation $\mathrm{mMG}$

$$
m M G=m . g, \text { jika } g>=T(A)
$$

In the table below is an image of the shape of each process from the overall process of this system

TABLE III

PROCESSING WITH MMG

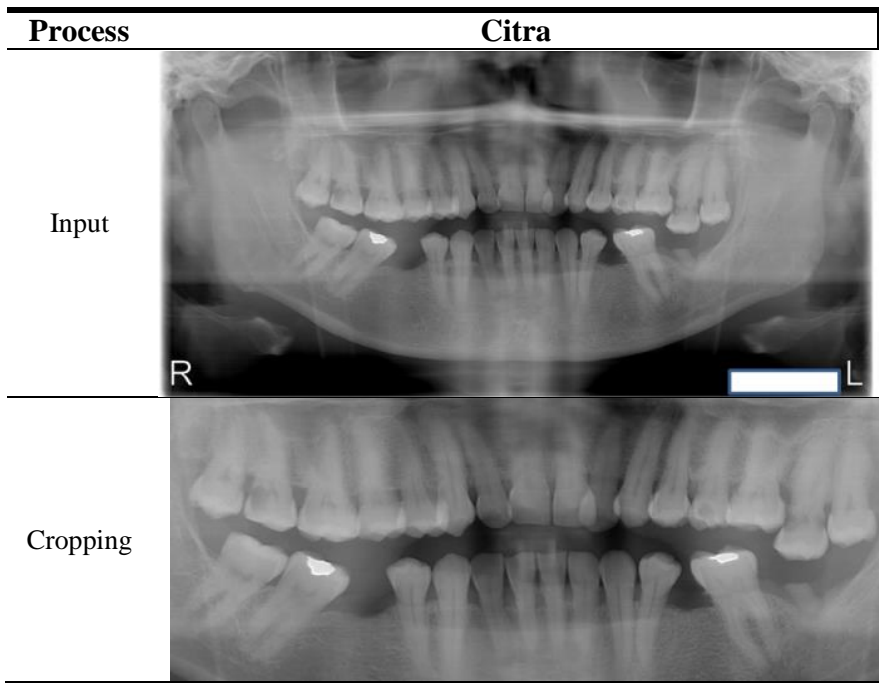




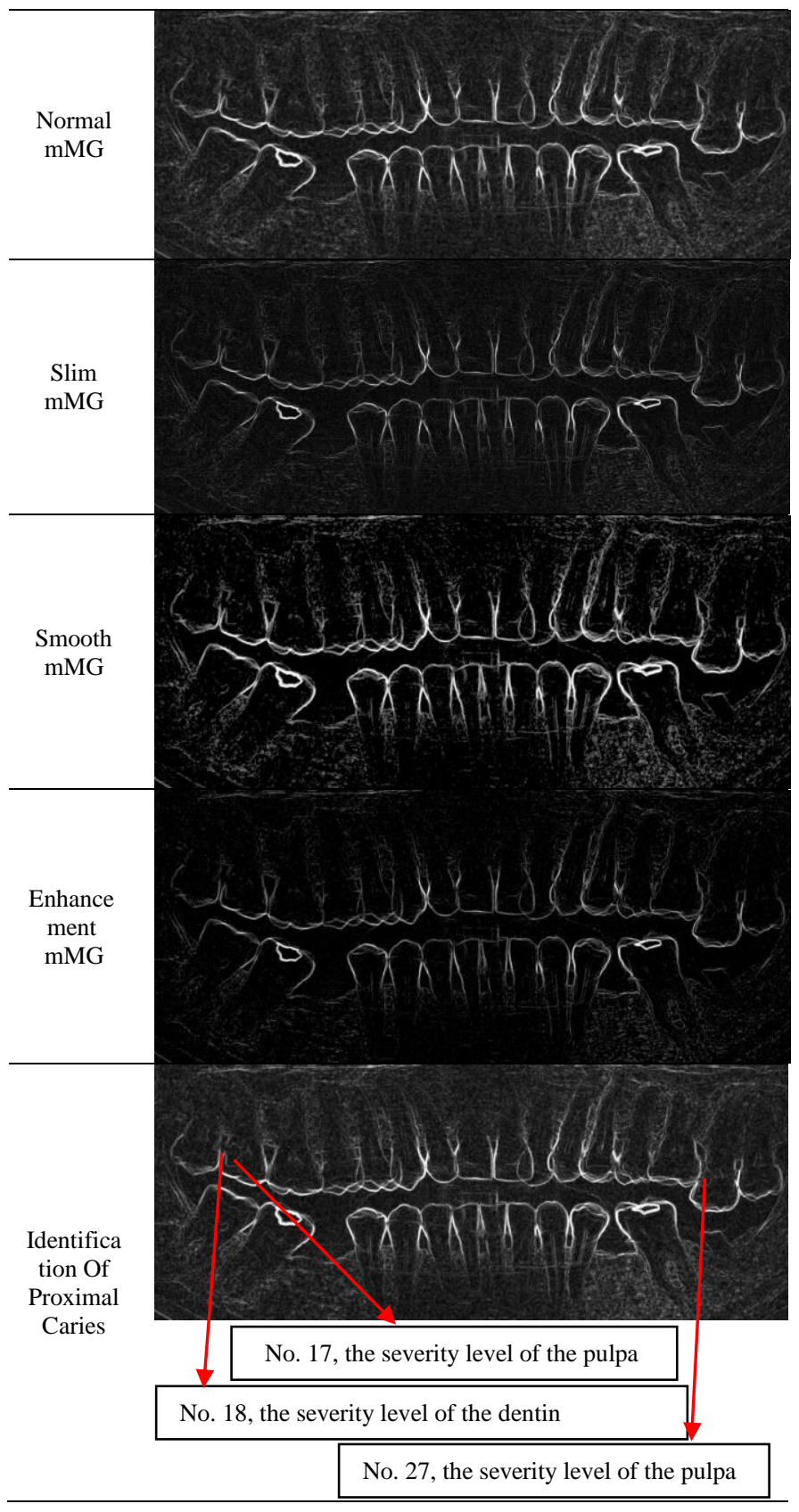

After all stages of the image of the proximal caries patients, the identification by the two dentists with proximal caries characteristics of the object as follows:

- boundary edges that connect teeth as proximal caries identity

- boundary edge that protrudes into the tooth (email, dentin or pulp) as an indicator of severity.

The results of the testing and data processing can be seen in the following table:

TABLE IIIII

RESULTS AND PROCESSING DATA

\begin{tabular}{|c|c|c|c|c|c|c|c|}
\hline \multirow{2}{*}{ No } & \multirow{2}{*}{ File Name } & \multicolumn{3}{|c|}{ Before } & \multicolumn{3}{|c|}{ After } \\
\hline & & $\mathbf{G}$ & $\mathbf{T}$ & amount & $\mathbf{G}$ & $\mathbf{T}$ & amount \\
\hline \multirow{2}{*}{1} & \multirow{2}{*}{ RSUP-Pano-001 } & \multirow{2}{*}{47} & \multirow{2}{*}{3} & \multirow{2}{*}{1} & 47 & 3 & \multirow{2}{*}{2} \\
\hline & & & & & 17 & 1 & \\
\hline \multirow{2}{*}{2} & \multirow[t]{2}{*}{ RSUP-Pano-006 } & 22 & 3 & \multirow{2}{*}{2} & 22 & 3 & \multirow{2}{*}{2} \\
\hline & & 32 & 3 & & 32 & 3 & \\
\hline
\end{tabular}

\begin{tabular}{|c|c|c|c|c|c|c|c|}
\hline \multirow{4}{*}{3} & \multirow{4}{*}{ RSUP-Pano-008 } & 21 & 2 & \multirow{4}{*}{3} & 21 & 2 & \multirow{4}{*}{4} \\
\hline & & 22 & 2 & & 22 & 2 & \\
\hline & & \multirow{2}{*}{41} & \multirow{2}{*}{2} & & 27 & 1 & \\
\hline & & & & & 41 & 2 & \\
\hline 4 & RSUP-Pano-009 & 36 & 3 & 1 & 36 & 3 & 1 \\
\hline \multirow{3}{*}{5} & \multirow{3}{*}{ RSUP-Pano-010 } & \multirow{3}{*}{17} & \multirow{3}{*}{3} & \multirow{3}{*}{1} & 17 & 3 & \multirow{3}{*}{3} \\
\hline & & & & & 18 & 1 & \\
\hline & & & & & 27 & 3 & \\
\hline \multirow{5}{*}{6} & \multirow{5}{*}{ RSUP-Pano-026 } & 13 & 2 & \multirow{5}{*}{3} & 13 & 2 & \multirow{5}{*}{5} \\
\hline & & 36 & 2 & & 36 & 2 & \\
\hline & & 30 & 2 & & 46 & 2 & \\
\hline & & 46 & 2 & & 47 & 1 & \\
\hline & & 70 & & & 26 & 2 & \\
\hline & & 38 & 3 & & 38 & 3 & \\
\hline 7 & RSUP-Pano-030 & 46 & 3 & 2 & 46 & 3 & 3 \\
\hline & & 70 & $J$ & & 27 & 2 & \\
\hline 8 & RSUP-Pano-032 & 37 & 2 & 1 & 37 & 2 & 1 \\
\hline 9 & RSUP_Pano_030 & 47 & 3 & 2 & 47 & 3 & 2 \\
\hline r & 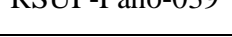 & 48 & 3 & 2 & 48 & 3 & 2 \\
\hline 10 & RSUP-Pano-045 & 46 & 3 & 1 & 46 & 3 & 1 \\
\hline 11 & RSUP-Pano-046 & 47 & 3 & 1 & 47 & 3 & 1 \\
\hline 12 & RSUP_Pano-048 & 27 & 2 & 1 & 27 & 2 & 2 \\
\hline & 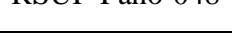 & & & & 17 & 1 & \\
\hline 13 & RSUP-Pano-062 & 37 & 3 & 1 & 37 & 3 & 1 \\
\hline 14 & DCUP Donn 066 & 17 & 3 & 2 & 17 & 3 & 2 \\
\hline 14 & KSUY-PAno-U00 & 18 & 3 & 2 & 18 & 3 & 2 \\
\hline 15 & RSUP_Pano_-069 & 47 & 2 & 1 & 47 & 2 & \\
\hline 15 & KSUP-Pano-069 & $4 /$ & 2 & 1 & 18 & 1 & 2 \\
\hline 16 & RSUP_Pano-072 & 27 & 3 & 2 & 27 & 3 & 2 \\
\hline 10 & КNUt- & 48 & 3 & 2 & 48 & 3 & 2 \\
\hline 17 & RSUP-Pano-073 & 47 & 3 & 1 & 47 & 3 & 1 \\
\hline 18 & RSUP-Pano-079 & 24 & 3 & 1 & 24 & 3 & 2 \\
\hline & & & & & 16 & 2 & \\
\hline & & 23 & 2 & & 23 & 2 & \\
\hline 10 & RSUP_Pann-080 & 24 & 3 & 3 & 24 & 3 & 4 \\
\hline & & 26 & 3 & & 25 & 3 & \\
\hline & & 20 & 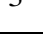 & & 26 & 3 & \\
\hline 20 & RSUP_Pano-082 & 37 & 2 & 1 & 37 & 2 & 2 \\
\hline & & & & & 47 & 2 & \\
\hline 21 & RSUP-Pano-084 & 47 & 2 & 1 & 47 & 2 & 2 \\
\hline & & & & & 38 & 2 & \\
\hline 22 & RSUP-Pano-087 & 38 & 2 & 1 & 38 & 2 & 1 \\
\hline 23 & RSUP-Pano-093 & 37 & 3 & 2 & 37 & 3 & 2 \\
\hline & & 47 & 3 & & 47 & 3 & \\
\hline & & & & & 46 & 3 & \\
\hline 24 & RSUP-Pano-095 & 46 & 3 & 1 & 17 & 1 & 3 \\
\hline & & & & & 18 & 1 & \\
\hline 25 & RSUP-Pano-096 & 46 & 3 & 1 & 46 & 3 & 2 \\
\hline & & & & & 27 & 2 & \\
\hline & & & & & 16 & 2 & \\
\hline 26 & RSUP-Pano-097 & 16 & 2 & 1 & 17 & 2 & 3 \\
\hline & & & & & 18 & 1 & \\
\hline & & 26 & 3 & & 26 & 3 & \\
\hline 27 & RSUP-Pano-101 & 35 & 2 & 2 & 35 & 2 & 3 \\
\hline & & JJ & 2 & & 34 & 2 & \\
\hline & Amount & & & 40 & & & 59 \\
\hline
\end{tabular}

Information :

- G: Number of proximal carious teeth

- T: The severity (1-Enamel; 2-Dentin; 3-pulp)

Improved accuracy for proximal caries detection with image processing: 
$\frac{59-40}{40} \times 100 \%=47.5 \%$

TABLE IVII

DETECTION PROXIMAL CARIES 27 PANORAMIC IMAGe BASED ON THE SEVERITY LEVEL BEFORE AND AFTER IMAGE PROCESSING

\begin{tabular}{ccc}
\hline The severity & $\begin{array}{c}\text { Pre- } \\
\text { processing } \\
\text { the image }\end{array}$ & $\begin{array}{c}\text { Post-processing the } \\
\text { image }\end{array}$ \\
\hline Enamel & 0 & 9 \\
Dentin & 15 & 23 \\
Pulpa & 25 & 27 \\
\hline Amount & 40 & 59 \\
\hline
\end{tabular}

Information:

- $\quad$ Severity: 1-Enamel; 2-Dentin; 3-pulp

- Many dental patients with proximal caries were identified after processing whereas prior to processing is not identified as much as $59-40=19$ teeth.

- Improved accuracy for the identification of proximal caries after processing is:

$$
\frac{19}{40} \times 100 \%=47,5 \%
$$

Distribution of proximal caries identification accuracy improvement based on severity are as follows:

TABLE VV

DISTRIBUTION FOR INCREASING THE ACCURACY IDENTIFICATION BASED PROXIMAL CARIES SEVERITY

\begin{tabular}{cllll}
\hline No & The severity & \multicolumn{2}{c}{ Percentage } \\
\hline 1 & Enamel & $\frac{9-0}{19} \times 100 \%$ & $47.4 \%$ \\
2 & Dentin & $\frac{23-15}{19} \times 100 \%$ & $=$ & $42.1 \%$ \\
3 & Pulpa & $\frac{27-25}{19} \times 100 \%$ & $=$ & $10.5 \%$ \\
\hline & Amount & & $100 \%$ \\
\hline
\end{tabular}

Based on the results of the calculation accuracy increase in distribution towards the proximal caries severity based on the above, the increased accuracy of identification of proximal caries with email being the highest level, i.e., $47.4 \%$, so that the system is better in detecting proximal caries rate of email or the initial level, so the patients sufferers of proximal caries of early responses can be solved by a dentist before becoming more severe.

\section{CONCLUSIONS}

The methods and algorithms mMG can clarify the image of Panoramic Dental X-Ray, so the intensity of the objects contained in the teeth can be improved as compared to the intensity of the tooth itself. mMG is much easier to identify proximal caries and caries severity of it, so it can be one of the indicators for the treatment of patients properly by a dentist. Improved detection accuracy of $47.5 \%$ with a correlation coefficient of $0.7181 . \mathrm{mMG}$ is also more precise method for identifying proximal caries enamel stage (beginning), so that patients with proximal caries can be treated early.

\section{ACKNOWLEDGMENT}

We would like to thank the Head of Department of Radiology, General Hospital of M. Djamil PadangIndonesia who have allowed us to acquire data from the Department of Radiology, General Hospital of M. Djamil Padang. Furthermore, we would like also to thank the dentists of Semen Padang Hospital and Regional Public Hospital Dabo Singkep who have helped us to analyze the images to be used in this study.

\section{REFERENCES}

[1] Crane R., A Simplified Approach to Image Processing Classical and Modern Techniques in C, Upper Saddle River: Prentice Hall PTR, 1997.

[2] Mount G.J. and Hume W.R., Preservation and Restoration of Tooth Structure, Australia: Knowledge Books and Software, 2005.

[3] Widodo S., "Segmentasi Otomatis Untuk Visualisasi 3-D Organ Paru Pada Citra Computer Tomography Menggunakan Active Countour", Jurnal Duta.com, vol. 1, no. 2, pp. 26-40, 2011.

[4] Madenda S., Pengolahan Citra \& Video Digital, Jakarta: Erlangga, 2015.

[5] White S.C. and Pharoah M.J, Oral Radiology: Principles and Interpretation, United States: Elsevier Health Sciences Mosby, 2009

[6] Hermawan R., Menyehatkan Daerah Mulut (Cara Praktis Menghilangkan Bau Mulut disertai Tips Agar Gigi dan Mulut Anda Selalu Sehat dan Indah, Jogjakarta: Buku Biru, 2012.

[7] Tikhe S.V., Naik A.M., Bhide S.D., Saravanan T. and Kaliyamurthie K.P., "Algorithm to Identify Enamel Caries and Interproximal Caries Using Dental Digital Radiographs", IEEE 6th International Conference on Advanced Computing (IACC), pp. 226-228, 2016.

[8] Pamplona M.C., Soriano Y.J. and Perez M.G.S., "Dental considerations in patients with heart disease", J Clin Exp Dent, vol 3, no. 2, pp. 97-105, 2011

[9] Summit, James B., Robbins J.W. and Schwartz R.S., Fundamentals of Operative Dentistry: A Contemporary Approach, Berlin: Quintessenz Verlag, 2011

[10] Ramesh T., Upendra G., Sravani K.B., Dathar S., Sinha P. Raghavendra M.N, Myla S. and Roja K., "A comparative study to diagnose the accuracy of E-speed film, complimentary metal oxide semiconductor and storage phosphor systems in the detection of proximal caries: An in vitro study", International Journal of Dental Research, vol. 4, no. 1, pp. 1-4, 2016.

[11] Sonis and Stephen T., Dental Secrets: Questions and Answers Reveal the Secrets to the Principles and Practice of Dentistry, Philadelphia: Hanley \& Belfus Inc., 2003.

[12] Abesi F., "Diagnostic accuracy of Digital and Conventional radiography in the detection of non-cavitated approximal dental caries", Iran J radiology, vol. 9, no. 1, pp. 17-21, 2012.

[13] Sainu R., Madhumala R., Thouseef, Majeed A., Ravi S., Sayeeganesh N. and Jayachandran D., "Imaging Techniques in Periodontics: A Review Article", Journal of Bioscience And Technology, vol. 7, no. 2, pp. 739-747, 2016.

[14] Rad A.E., Rahim M.S., Norouzi A., "Digital Dental X-Ray Image Segmentation and Feature Extraction", TELKOMNIKA Indonesian Journal of Electrical Engineering, vol. 11, no. 6, pp. 3109-3114, 2013.

[15] Angkoso C.V., Ingrid N., Ketut E.P. and Mauridhi H.P., Analisa Tekstur Untuk Membedakan Kista Dan Tumor pada Citra Panoramik Rahang Gigi Manusia, , ITS Surabaya: The 12th Seminar Intelligent Technology and Applicatin, 2011.

[16] Ahmed El-Rafei and Tobias Engelhorn, Computational Vision and Medical Image Processing: Recent Trends, Netherlands: Springer, 2011.

[17] Akarslan Z.Z., Akdevelionglu M., Gungor K. and Erten H., "A comparison of the diagnostic accuracy of bitewing, periapical, unfiltered and filtered digital panoramic images for approximal 
caries detection in posterior teeth", Dentomaxillofacial Radiology, vol. 37, no. 8, pp. 458-463, 2008.

[18] Kamburoglu K., Kolsuz E., Murat S., Yüksel S. and Ozen T., "Proximal caries detection accuracy using intraoral bitewing radiography, extraoral bitewing radiography and panoramic radiography", Dento Maxillo Facial Radiol, vol. 42, no. 1, pp. 450459, 2012.

[19] Hoseini Z.S.H., Javadian L.A. and Shafagh M.M. (2013), "Comparison between Two Digital Panoramic Radiography Techniques for Proximal Caries Detection", J Dent Mater Tech, vol 2, no. 2, pp. 54-58, 2013.

[20] Abdinian M., Razavi S.M., Faghihian R., Samety A.A. and Faghihian E., "Accuracy of Digital Bitewing Radiography versus Different Views of Digital Panoramic Radiography for Detection of Proximal Caries", Journal of Dentistry, vol. 12, no. 4, pp. 290-297, 2015.

[21] Sabarinathan K.M., Mahalakshmi M., Shoba B., Vidhya S., Siva P.G., Dhanesh K.K. and Natarajan V.G.. "Identification of Tooth Decay in Panoramic X-ray using Image Processing", Australian Journal of Basic and Applied Sciences, vol. 9, no. 6, pp. 60-64, 2015.

[22] Tafakhori Z., Khazaei M. and Afshari P.A., "Accuracy of Digital Panoramic Imaging in Detection of Proximal Caries in Posterior Teeth”, Sadra Med Sci J, vol. 4, no. 2, pp. 99-106, 2016.

[23] Terry G.L., Noujeim M., Langlais R.P., Moore W.S. and Prihoda T.J., "A clinical comparison of extraoral panoramic and intraoral radiographic modalities for detecting proximal caries and visualizing open posterior interproximal contacts", Dentomaxillofacial Radiology, vol. 45, no. 4, pp. 1-7, 2016.

[24] Valizadeh S., Goodini M., Ehsani S., Mohseni H., Azimi F. dan Bakhshandeh H., "Designing of a Computer Software for Detection of Approximal Caries in Posterior Teeth", Iran J Radiol, vol. 12, no. 4, pp. 1-5, 2015

[25] Mohtavipour S.T. and Javadzadeh H.A. (2016), "Comparison of digital panoramic and bite-wing radiography in proximal caries detection of molar teeth", J Isfahan Dent Sch, vol. 11, no. 6, pp. 531533, 2016.

[26] Li X., Abaza A., Nassar D.E. and Ammar H.,"Fast And Accurate Segmentation of Dental X-Ray Records", Journal of Engineering and Technology, vol. 2, no. 8, pp. 688-697, 2005

[27] Eyad H.S., Gamal F., Nassar A. and Ammar A., "Dental X-ray Image Segmentation", International Journal on Computer Science and Electrical Engineering, vol. 5, no. 4, pp. 1-13, 2006.

[28] Chen J., Bai G., Liang S. and Li Z., Automatic Image Cropping : A Computational Complexity Study, Las Vegas: The IEEE Conference on Computer Vision and Pattern Recognition (CVPR) in Computer Vision Foundation (CVF), 2016.

[29] Julius S. and Jufriadif N., Infiltrate Object Extraction in X-ray Image by using Math-Morphology Method and Feature Region Analysis, International Journal on Advanced Science, Engineering and Information Technology, vol. 6, no. 2, pp. 239-244, 2016

[30] Na`am J., Harlan J., Madenda S. and Wibowo E.P. (2016), "Identification of the Proximal Caries of Dental X-Ray Image with Multiple Morphology Gradient Method", International Journal on Advanced Science, Engineering and Information Technology, vol. 6, no. 3, pp. 343-346, 2016.

[31] Kadir A. and Susanto A., Pegolahan Citra Teori dan Aplikasi, Yogyakarta: Andi Publisher, 2012.

[32] Na am J., Harlan J., Madenda S. dan Wibowo E.P., "The Algorithm of Image Edge Detection on Panoramic Dental X-Ray Using Multiple Morphological Gradient (mMG) Method", International Journal on Advanced Science, Engineering and Information Technology, vol. 6, no. 6, pp. 2012-2018, 2016.

[33] Burger W. and Burge M.J., Digital Image Processing An Algorithmic Introduction Using Java, Springer, London, 2016. 